\title{
Ontological Paraconsistency Has a Place
}

\author{
Marcia Ricci Pinheiro
}

IICSE University, Wilmington, USA

\section{Email address:}

drmarciapinheiro@gmail.com

\section{To cite this article:}

Marcia Ricci Pinheiro. Ontological Paraconsistency Has a Place. International Journal of Philosophy. Vol. 4, No. 1, 2016, pp. 1-6. doi: $10.11648 /$ j.ijp.20160401.11

Received: March 19, 2016; Accepted: March 28, 2016; Published: April 21, 2016

\begin{abstract}
In this paper, we recover the idea cast by Graham Priest to our ears in 2000: That it was possible to experience Ontological Paraconsistency in life. He had, back then, as a translation of his thinking, a painting by Escher: The stairs could be going up or down, and one could not tell where they were going by simply examining the painting. The most obvious argument as to why that was not an instance of Ontological Paraconsistency found in reality was that the perspective from which you would have to stare at the painting to see something different would be different too, so that it was impossible that we were getting up and down at the same time, that is, from the same perspective. That would happen with anything we picked in this world. We recently found something that does not entirely belong to this world, however, something that could finally satisfy the requirements of Priest, and therefore prove to us that there is a place for Ontological Paraconsistency. We observe that the paraconsistent robot, Emmy (Abe et al., 2006), is an application of the Non-ontological Paraconsistency, which we always believed to be passive of existence, but we here talk about another type of paraconsistency, which would be intrinsic to the being. The purpose of this paper is then providing a definite answer to the questions: Is there any real life instance of Ontological Paraconsistency? Is Ontological Paraconsistency a useful concept in terms of logical theories?
\end{abstract}

Keywords: Paraconsistency, Priest, Da Costa, Ontological, Tanaka, Non-ontological, Classical Logic, Escher

\section{Introduction}

The difference between intrinsic and extrinsic paraconsistency, or between ontological and non-ontological paraconsistency, is that one brings, for instance, inconsistencies to our perceptions as a set of paradigms, so that we may believe that something is round and also square, say when people were yet to start spatial explorations and some theories said that the world was a cube or something similar to that whilst others said that it was a ball or something similar to that (there is a conflicting pair of members in our beliefs set, if human kind is considered as one thing, since we believe that something is rounded but we also believe that it is not rounded, percentages and all else ignored) and the other brings inconsistencies to the own being, which sometimes may be us.

When we say that the inconsistency is intrinsic, we could have the same individual using the same paradigms, and reaching different conclusions or the object being round and square at the same time, not our perception of it.

Our point, which we made clear to Priest in 2000 , is that, when the individual says, this is $X$, they have a set of paradigms $\mathrm{W}$ in their mind, but, when they say, this is not $X$, they have another set of paradigms, so say W'.

With this, the object of observation is not both $\mathrm{X}$ and not$\mathrm{X}$, it is something independent, and we talk about perceptions and different paradigms each time.

With Emmy or any other robot made out of Paraconsistent Logic, there would be inconsistencies in the perceptions of the robot, and those can now be addressed. They were not being addressed before, however, not with Classical Logic. Now, it suffices programming the robot to perform action $Y$ instead of crashing when conflict arises. All we are doing is avoiding the Law of the Explosion in this case.

We see the object as something invariably connected to our perception, that is, the object does not exist per se as something. We give a name to the perception paradigms of the vast majority when observing that object, so say moon, but that does not mean that everyone on earth has agreed that that object is the moon. Some may think it is cheese, for instance, and never drop that belief.

A person who loves another, so say $\mathrm{M}$ loves $\mathrm{N}$, may also 
not love, that is, M may not love $\mathrm{N}$, and that is common in human kind. For instance, the same guy who married a woman at the Catholic Church and promised, before the priest and the church attendees, to love that woman forever and ever may kill her all of a sudden. The thing, however, is that this guy does not love and love at the same time or because of the same reasons, and that is obvious: Perhaps he wants to kill her because he believes she betrayed him and he loved her because he believed that she was beautiful. She was beautiful and he loved her on a Monday. She was a traitor and he killed her on a Friday.

In this way, the conflicting feelings of this individual do not make him inconsistent and the own feelings are not inconsistent either if put together with the context, which is what we always have to do to analyse real life situations well.

The Sorites could be a problem for Classical Logic if out of context, if totally modified, as we explained in (Pinheiro, 2016), but it is not a Classical Logic problem inside of the context in which it is originally presented.

Real life makes a lot of difference and we explain that also in Words for Science (Pinheiro, 2015b).

How can a person be black and white? Say Michael Jackson is black and white like he himself says. He is black because he was born black, but he is white because he acquired the colour white. Once more, the moments in time are distinct and so are the paradigms involved: When we say that he is black, we think of his birth and the aspect of his skin. When we say he is white, we think of the moment of his death and the aspect of his skin.

Even though aspect of skin is seen on both occasions, the other paradigm is different, providing us with $\mathrm{W}$ and $\mathrm{W}$ ' instead of $\mathrm{W}$ and $\mathrm{W}$, what then explains why this is not an example of application of Ontological Paraconsistency, only at most an application of Non-ontological Paraconsistency.

In thinking like that, we concluded that nothing that we see as normal could fit the concept of Ontological Paraconsistency, but something like God could: Something mystical or almost purely abstract.

\section{About God and Paraconsistency}

With God, our beliefs are inconsistent at least sometimes if considered in isolation: $\mathrm{He}$ is good because He helped me win here. He is bad because He made me lose there.

The thing is that the own God is inconsistent if we consider that God is, for instance, His told-to-be declarations, what we see in the Catholic Bible: He says, Do not kill (Mark, 2016). He also says (in other words), Sacrifice sheep for me (Exodus, 2016).

That is clearly Kill and Do Not Kill because we don't know what He was thinking when He said Do Not Kill, and therefore it may as well be that it was about sheep and now we have both Kill and Do Not Kill with precisely the same contextual supplement, all coming from God.

Some think that God is a person and the Bible seems to deal with God like that: We are the image of God.

Some think that God is energy and materializes Himself as whatever He likes, so that He appeared in the skies for Jesus, but appeared in person in the shape of Jesus to others.

The beliefs of people are inconsistent in what regards God, but, once more, the paradigms are different: We have $\mathrm{W}$ and W' when that happens.

With the same people observing, however, and with those people having the same beliefs, so say no pre-established belief, and the same God, we could have God in the skies and God as Jesus, what then could make of God an example of application of Ontological Paraconsistency: He is Jesus but He isn't. When we see Him in the skies speaking to Jesus, then He isn't. When we see Jesus and believe that He is God, then $\mathrm{He}$ is.

Our set of beliefs could be that God is the unknown. In this case, God is both Jesus and the thing in the skies speaking to Jesus.

When we see a certain book and say, It is English, but it isn't, we may imply that the language of the book is definitely English, but it is impossible to understand it because it is Ancient English. We then mean Modern English when we said English and Ancient English is not Modern English, so that this is another language in that sense. It is still all about English and we do have the same paradigm in our mind when we say that, right? Notwithstanding, when we say Ancient English, we have the paradigm ancient words in our heads and when we say English, we have the paradigm modern words in our heads, so that this is still about different things, not Ontological Paraconsistency, since Ontological Paraconsistency happens neither inside of us nor inside of the book.

That must be why they created the concept of Holy Trinity: Father, Son, and Holy Spirit.

It seems that, at the same time, with the same paradigms, we see God as all of them.

\section{About Escher and Paraconsistency}

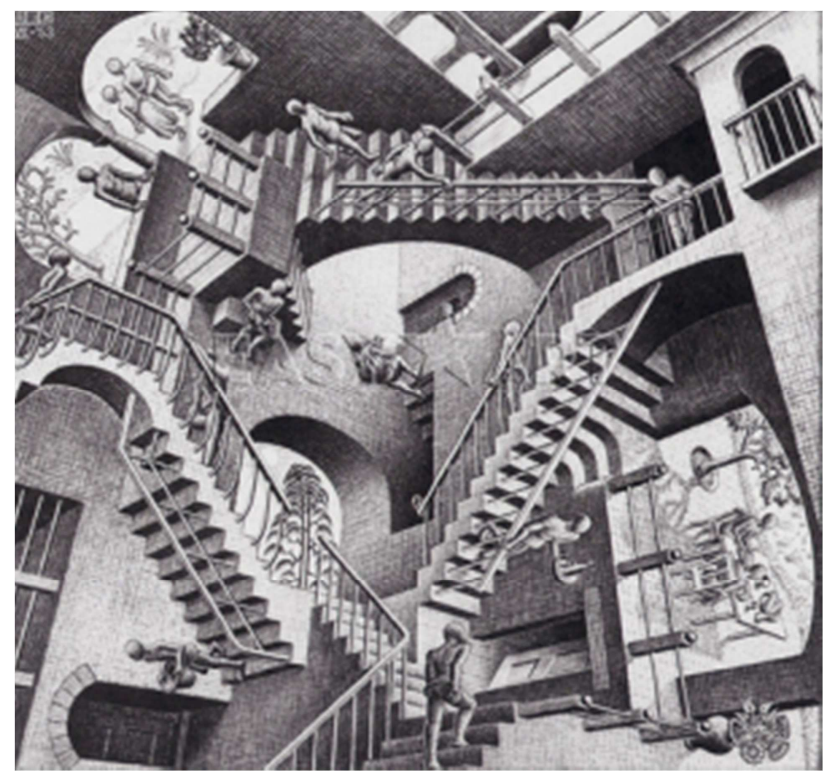

Fig. 1. Esher's Relativity (Shivprasad, 2011). 
The picture that you have just seen portrays a famous painting of Esher that Graham Priest used to explain Ontological Paraconsistency better in that 2000 at the University of Queensland (RIES, 2013).

In the painting, things would both be and not be, which should then make us believe that Ontological Paraconsistency is a reality.

Shivprasad (2011) talks about Relativity in the following way:

In Relativity Escher plays with our orientation of dimensions. We just cannot be sure where the ground is and where the sky is. The feet of the characters in Relativity could well be planted in the sky but one man's sky is the other man's ground: another paradoxical thought. Relativity is portrayed extensively in a succession of scenes in which Cobb introduces Ariadne to the basics of creating architecture for a dream. When they are walking the streets of Paris, the ground folds up, and becomes the sky. Buildings are seen inverted. Roads with cars running on them are seen in the sky. When Cobb and Ariadne begin walking, they climb up vertical roads and walk just as they would on the ground, just like the characters from Relativity.

Esher himself says (Kammer, 2014), in 1963:

I cannot help mocking all our unwavering certainties. It is, for example, great fun deliberately to confuse two and three dimensions, the plane and space, or to poke fun at gravity. Are you sure that a floor cannot also be a ceiling? Are you absolutely certain that you go up when you walk up a staircase?

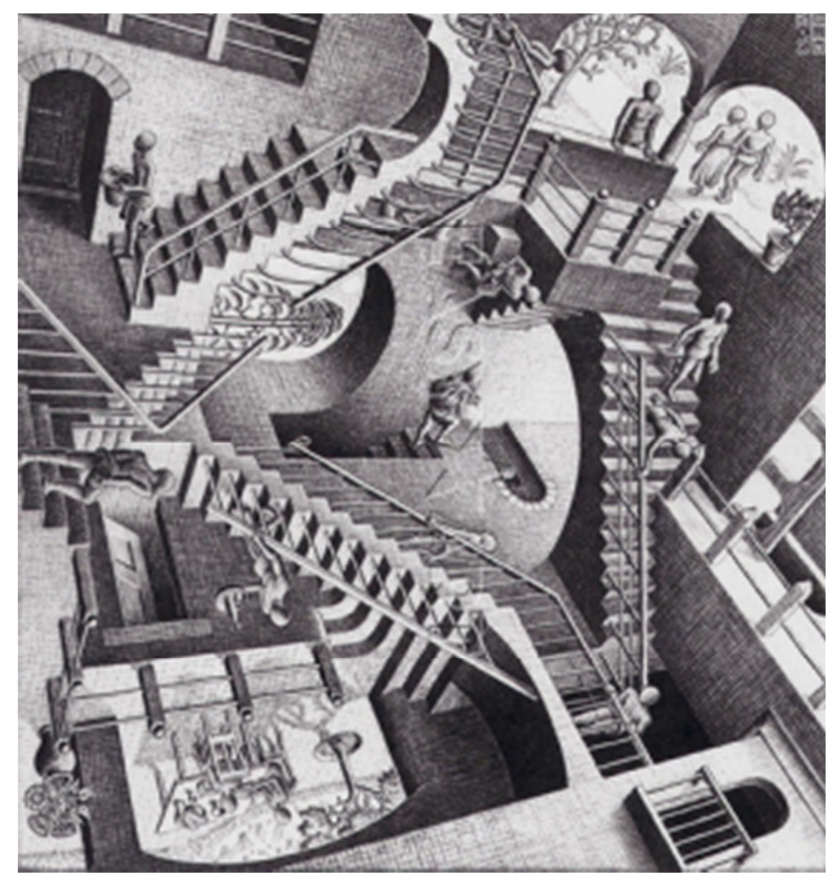

Fig. 2. Observe the guy that carries the candle. He seems to be going upstairs, right? The two guys to the right: One seems to be going downstairs and the other seems to be starting to hold the support, so that he can go upstairs or even downstairs after he succeeds.

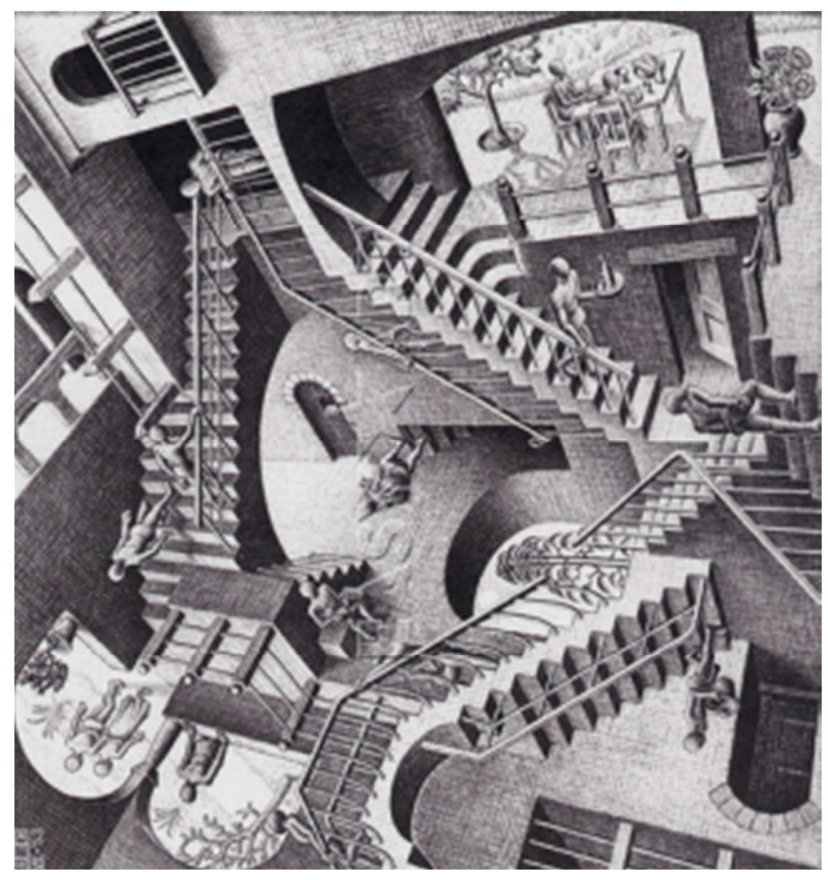

Fig. 3. The guy who carries the candle looks as if he is going downstairs. The two guys to the left look as if they are going upstairs in a weird manner.

The basic problem, as explained before, is that, when we see the guy with the candle going upstairs, the angle of our sight is W, let's say, but, when we see him going downstairs, the angle is W', what we noticed in the own 2000. In this case, it is not the same things that both are and are not, since our angle of sight has changed, and therefore our mental paradigms. Things present themselves in a way $\mathrm{X}$ from angle $\mathrm{W}$ and in a way $\mathrm{X}$ ' from angle $\mathrm{W}$ '. Then one could claim that they are paraconsistent, and Priest would probably say that they are.

We would say that a person of $1.72 \mathrm{~m}$ may look tall if put together with a pigmy and short if put together with a giant, say a guy who is $2.5 \mathrm{~m}$ tall. It is the same person and that does not make them short and not-short at the same time: They are relatively short at a time $\mathrm{Y}$ and relatively tall at a time $\mathrm{U}$, different from $Y$, and therefore not at the same time. The perspective of those observing has also changed: First, they had the extremely short person to compare the basic height with, then they had the extremely tall person. The height of the person being observed, however, never changed: What changed was the perspective of those observing due to paradigms that were introduced around the person. In a certain town, we could say that a man of $1.72 \mathrm{~m}$ has a regular height, so that his height is always regular, never high or low, regardless.

As we turn the picture of the painting, the angle of observation changes as well as what we see close to any selected point, which is the same that happens to the person whose height was observed in the previous paragraph, and therefore those selected points have not changed and are not paraconsistent entities.

One could also argue that this is the same we see in the example with God and Jesus: When we observe Him with 
Jesus, we see things from a certain perspective and together with a set of paradigms, say W. When we observe Jesus on his own, we see things from another perspective together with a new set of paradigms, say W'. Notwithstanding, our idea of what God is in our case, the unknown, has not changed, and therefore our basic paradigm has never changed. We see Jesus and his shape with no mistake and no change in what we see, regardless of the perspective, different from what happens with Escher's painting. We see God and His shape with no mistake and no change in what we see, also regardless of the perspective. What is happening here is that both will fit our definition of God with no mistake and in the same way. In this case, we are obliged to agree that God both is and isn't Jesus. Even so, before we see God speaking to Jesus from the clouds, God is Jesus and Jesus only. It is only after we see God speaking to Jesus in that way that we think God may be something else or also something else, and perhaps Jesus is a human like us compared to that something else. We have more context, more information, and therefore other paradigms ALSO here. Jesus is then God for us, but perhaps he is a lesser god or something not as unknown as the other god. These paradigms, the ones that differ here, would be something like revealing more pieces of the painting of Escher, so say they found out that part of his painting was actually hidden behind the frame and now we have more data. This is something completely different from simply turning the picture and seeing from another angle. Yet, this ALSO promotes a change of paradigms that is non-negligible.

The thing is that if it all depends on our observation, what is inside of our minds, then it is not the object of our observation that is inconsistent, but at most our private logic. As our private logic could be described by a special logical system, this paraconsistency is non-ontological.

We can draw a set and call it Unknown. In this set, we may insert Jesus. Now the idea is clear: Unknown is Jesus, since Jesus is inside of Unknown. Notwithstanding, Unknown is not Jesus because Unknown is more than Jesus. Once more, we have the perspectives being different, right? In one case, we only see Jesus inside and we then say that Unknown is Jesus. In the other case, we see the rest, perhaps finally, then Unknown is not Jesus or Unknown is not only Jesus.

If we consider that different people have different beliefs about God, however, and we take them all to be true because, for instance, they all seem to have passed through miraculous processes, God could end up being a person and a nonperson, so say we take the Catholic belief, that Jesus was God, and therefore human during His life on earth, and the belief of The Empire (Pinheiro, 2015), that Jesus was just a normal human and, if God has something to do with him, then $\mathrm{He}$ has to do with us in the same way. The Empire believes that God was never human.

In this case, God is both a human and a non-human and $\mathrm{He}$ is then paraconsistent.

Each religion that we have just mentioned has their own perspective, but our perspective, of those observing them, is the same: They have miracles to present and therefore their gods should all be our God. In this case, God is both human and non-human at the same time. Even though our explanation for that is that those religions say that He is such and such and they have such and such miracles, God must still satisfy all that to be the only god we have, and this was our decision here. In this case, He must be both human and non-human, therefore paraconsistent in what regards at least this aspect.

Perhaps it is worth examining a few more pictures:

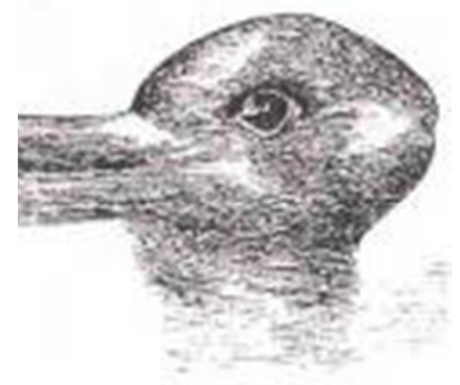

Fig. 4. Duck Rabbit Illusion (Illusionist.com, 2015).

In this picture, we should see a duck if we look at it from right to left and a rabbit if we look at it from left to right. It is probably clearer here: It all depends on the angle of our sight, and therefore the conflicting impressions do not come from the same origin, what then makes each one of the impressions happen at a different time, not at the same time, as it would be essential for us to claim that this is a real-life instance of the phenomenon Ontological Paraconsistency.

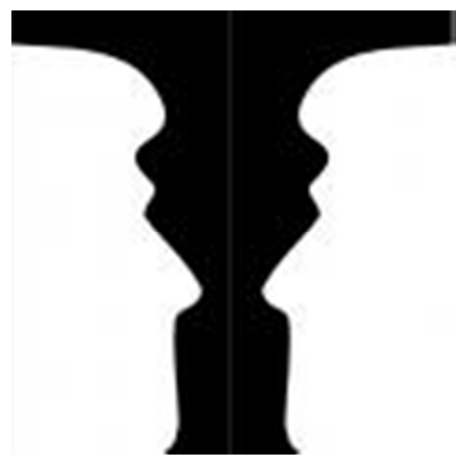

Fig. 5. Candlestick Illusion (Illusionist.com, 2015).

In this picture, we should see two people if we fixate our eyes on the white part and a candlestick if we fixate them on the black part. Once more, things do not happen at the same time. Maybe, however, for other types of entities, it would be possible to see both at the same time. Maybe there are special illnesses or genetic modifications that would allow our eyes to see both images, faces and candlestick, at the same time. In those special cases, it would be possible to assert that this is an instance of Ontological Paraconsistency, finally, like if our eyes never moved and our thinking never changed, then we could probably say that it is if we see both at the same time. In human race as we know it, however, this is not an instance of Ontological Paraconsistency. 


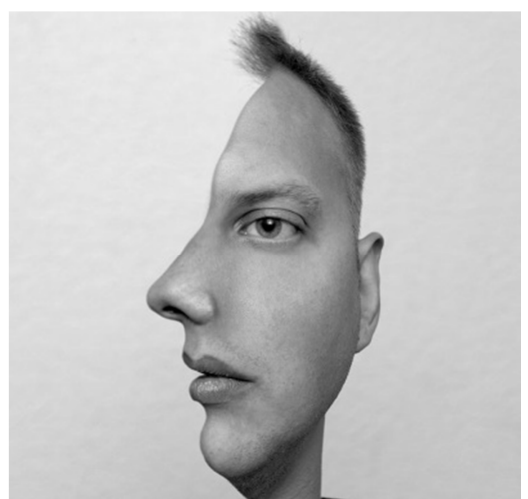

Fig. 6. Double Face (Pixdaus Ltd., 2016).

Here, what we see is a frontal picture of half of a face if we fixate the eyes on the ear of the character and a full picture, of the type caricature, of the side of a face if we fixate our eyes on the nose and mouth that we see to the left. As just said, the eyes go different places to see different things, so that this is NOT an example of Ontological Paraconsistency.

\section{Conclusion}

We seemed to be stuck with concluding that there is no such a thing as Ontological Paraconsistency, that all that there is is Non-ontological Paraconsistency, as Da Costa apparently believes, this according to what Priest said by means of personal communications in 2000 to us, and according to what Tanaka said in (Tanaka, 2003). Tanaka replaces the term Ontological Paraconsistency with perhaps an expression, accepting of true contradictions. True contradictions is a term that obviously implies contradictions that exist as a fact in the world. If they exist as a fact, then things are ontologically paraconsistent, which is our choice of terms here.

It seems that whatever thing we attempt to put in the bag of Ontological Paraconsistency will end up either presenting different paradigms, as in $\mathrm{W}$ and $\mathrm{W}^{\prime}$, in the analysis when the conclusion is that it should be or will end up allowing for the creation of a logical system, what then makes it all be nonontological.

Escher's painting is a true inspiration but it more represents a puzzle than an example of Ontological Paraconsistency: It is a paradox up to the point at which we find out that there has to be a change in perspective and even in the context for us to end up asserting two conflicting things about the items in the painting.

Not even God suffers from Ontological Paraconsistency because the perspectives and contexts will be different when we reach conflicting conclusions. There is a case, however, a case involving us defining what God is based on what is stated by human kind, that proves that God may suffer from Ontological Paraconsistency: In this case, we have a group of humans and we say that we must have only one god. All their definitions of God, or all their beliefs about God, would have to be true at the same time. That is when we could say that God both is and isn't something, so say human.
The difference between this example and the situation in which we have The Bible in front of us and a group of people saying that it is blue whilst another group is saying that it is green is that we ourselves are going to say that it is either blue or green when somebody asks us what we think about it. Now, if we say that it is both green and blue, then we are actually seeing green from one perspective, a set of paradigms $\mathrm{W}$, and blue from another perspective, a set of paradigms W', what then does not give an example of Ontological Paraconsistency, just confusion in the description of our observations/perceptions. We can obviously write a code to explain that, that is, we can express that by means of a programming language. Whatever fits a programming language is part of the phenomenon Non-ontological Paraconsistency instead. It is not the object that is both blue and green, but our perception that is confusing, our association between sigmatoids and world objects, that is, it is our perception that is not being well described. Notwithstanding, it could be perfectly described by means of the human language too.

Perhaps any non-animated object would have to not suffer from Ontological Paraconsistency, since it actually depends on us acknowledging its existence to become something, and something we invent, with our abstract world, that they are. In this case, what we invent that they are depends on our perception, our human perception, and therefore the only entities that could suffer from Ontological Paraconsistency would be us. In this case, we would have to be and not to be at the same time, considering the same perspective or the same paradigms, for us to be able to say that we are Ontologically Paraconsistent. The example we here mention, about the human marriage, should make this all clearer.

\section{References}

[1] Exodus 20_24 KJV - An altar of earth thou shalt make unto Bible Gateway. (n.d.). Retrieved February 29, 2016, from https://www.biblegateway.com/passage/?search=Exodus $+20: 2$ $4 \&$ version $=\mathrm{KJV}$

[2] Illusionist.com. (2015). Double Meanings. Retrieved March 26, 2016, from http://www.opticalillusionist.com/category/double-meanings/

[3] Inácio, J., Torres, C. R., Abe, M., \& Filho, D. S. (2006). Robô Móvel Autônomo Emmy (Autonomous Mobile Robot, Emmy): Uma Aplicação eficiente da Lógica Paraconsistente Anotada (An efficient application of the annotated paraconsistent logic), 19-26.

[4] Kammer, C. (2014). Esher's impossible stairs inspired by high school stairwell. Retrieved March 26, 2016, from http://www.nrc.nl/nieuws/2014/11/16/eschers-impossiblestairs-inspired-by-high-school

[5] Mark 10_19 KJV - Thou knowest the commandments, Do not - Bible Gateway. (n.d.). Retrieved February 29, 2016, from https://www.biblegateway.com/passage/?search=Mark+10:19 \&version $=\mathrm{KJV}$ 
[6] Pinheiro, M. R. (2015). (August 2015). The Empire of God. Retrieved February 28, 2016, from http://theempireofgod.blogspot.com.au/2015 08 01 archive.h tml

[7] Pinheiro, M. R. (2015b). Words for Science. Indian Journal of Applied Research, 5(5), 19-22. Retrieved from https://www.worldwidejournals.com/ijar/articles.php?val=NjQ $0 \mathrm{MQ}==\& \mathrm{~b} 1=853 \& \mathrm{k}=214$

[8] Pinheiro, M. R. (2016). FIRST DECISIONS: NATURE OF THE MODELLING WORK.

[9] Pixdaus Ltd. (2016). Pixdaus. Retrieved March 26, 2016, from http://pixdaus.com/double-face-photo-by-jdtnt-illusionappearing-as-two-faces/items/view/579957/
[10] Priest, G., Tanaka, K., \& Weber, Z. (2013). Ecology (Stanford Encyclopedia of Philosophy). Retrieved from http://plato.stanford.edu/entries/logic-paraconsistent/

[11] RIES RAMON LLULL. (2013). escalator «Bla, bla, bla 3. Retrieved February 27, 2016, from https://1eso1314.wordpress.com/tag/escalator/

[12] Shivprasad. (2011). Inception and its Inspirations: Esher, Dali and Yoga Vasistha. Retrieved March 26, 2016, from http://www.criticaltwenties.in/philosophyreligionculture/incep tion-and-its-inspirations-escher-dali-and-yoga-vasistha

[13] Tanaka, K. (2003). Three Schools of Paraconsistency. Australasian Journal of Logic, 1(1), 28-42. Retrieved from http://philosophy.unimelb.edu.au/aj1/2003/ 